\title{
Review Article \\ Health View to Decrease Negative Effect of High Heels Wearing: A Systemic Review
}

\author{
Meizi Wang, ${ }^{1,2}$ Ci Jiang $\mathbb{D}^{1},{ }^{1}$ Gusztáv Fekete, ${ }^{3}$ Ee-Chon Teo, ${ }^{1}$ and Yaodong Gu $\mathbb{D}^{1}$ \\ ${ }^{1}$ Faculty of Sports Science, Ningbo University, Ningbo, China \\ ${ }^{2}$ Faculty of Engineering, University of Pannonia, Veszprem, Hungary \\ ${ }^{3}$ Savaria Institute of Technology, Eötvös Loránd University, Hungary \\ Correspondence should be addressed to Ci Jiang; davidmaowl@gmail.com
}

Received 20 October 2020; Revised 5 February 2021; Accepted 4 March 2021; Published 15 March 2021

Academic Editor: Donato Romano

Copyright @ 2021 Meizi Wang et al. This is an open access article distributed under the Creative Commons Attribution License, which permits unrestricted use, distribution, and reproduction in any medium, provided the original work is properly cited.

Effective recommendations about how to decrease adverse effects of high heels $(\mathrm{HH})$ need to be provided, since wearing $\mathrm{HH}$ is inevitable for most women in their daily life, regardless of their negative impacts on the foot morphology. The main purpose of this systematic review was to summarize studies which have provided specific information about how to effectively offset the negative effects of wearing $\mathrm{HH}$, in the case of women, by means of examining heel height, insole, and heel base support (HBS). Some evidence indicate the following: (i) the range of appropriate heel height for $\mathrm{HH}$ shoes is $3.76 \mathrm{~cm}$ to $4.47 \mathrm{~cm}$; (ii) compared to small HBS, the larger ones effectively increase gait stability, reduce risk of ankle injury, and improve comfort rating during $\mathrm{HH}$ walking; and (iii) the use of a total contact insert (TCI) significantly decreases plantar pressure and the impact on the foot, resulting in higher perceived comfort. It must be noted that these results are based on short-term research; therefore, any conclusions with regard to effects in the long term should be taken with a grain of salt. Nevertheless, future studies should be aimed at combining numerical and experimental methods, in order to provide personal recommendations for $\mathrm{HH}$ shoes by considering heel height and HBS size, based on the individual characters (weight, height, and age).

\section{Introduction}

The potential impact of HH shoes on women's health for over 50 years has been of concern in medical circles. Studies have shown that wearing $\mathrm{HH}$ can lead to slower self-selected walking speed, shorter step length, and smaller stance phase duration, while it increases ankle plantar flexion, knee plantar flexion, anterior pelvic tilt, and trunk extension [1-7]. Redistributing the plantar pressure, higher ground reaction forces (GRF), larger loading rate, higher peak knee external adduction moments, and higher peak patellofemoral joint stress have been detected during walking in $\mathrm{HH}[8-11]$. It is worthy to note that substantial bodily adjustments have been observed due to wearing $\mathrm{HH}$, e.g., change in the neuromuscular activation pattern, shortening of the gastrocnemius muscle fascicle muscles, increase in the Achilles tendon stiffness, and higher muscle activity of the soleus, tibialis anterior, and medial gastrocnemius [12-14]. These above-mentioned disturbances have been identified as negative implications for the human body. It is presumed that they contribute to several pathologies including metatarsalgia, hallux valgus, Achilles tendon tightness, knee osteoarthritis (OA), plantar fasciitis, and lower back pain, not to mention the elevated instability and imbalance, which can result in a greater risk of falling and slipping [15-19].

Despite widespread warnings from public health institutions and international medical societies [20], there is still a large proportion of the population wearing $\mathrm{HH}$ in their daily life. Regarding why women choose to wear $\mathrm{HH}$, Broega et al. surveyed 574 females, between the ages of 24 and 45 , who indicated that beauty and femininity were the key drivers of women's behavior [21]. Therefore, accurate suggestions must be provided about how to counter the adverse effects of $\mathrm{HH}$ using, instead of only giving a simple advice on not wearing 
it. Consequently, in the near future, the design of $\mathrm{HH}$ shoes must be associated to comfort and aesthetics in order to meet the requirements of beauty and health.

Up to now, researchers have made significant efforts to improve comfort of high-heeled shoes by suggesting a suitable heel height, an appropriate insert insole, sufficient support area of the heel, and even walking speed during $\mathrm{HH}$ gait. Studies have shown that an optimal range of height for maintaining postural balance and stability is between 3 and $5 \mathrm{~cm} \mathrm{[2,}$ 17, 18]. Yung and Wei observed that a TCI, coupled with a metatarsal pad, arch support, and heel-cup mechanism, redistributed the plantar pressure, and as a consequence, it decreased the impact force by $33.2 \%$ in the case of $\mathrm{HH}$ [22]. It was also considered that small HBS increased the deviation of the center of pressure (COP), which on the one hand caused larger foot pressure in the rearfoot region, and on the other hand, it disturbed the muscle activity pattern [22].

However, the effects of physiology and ergonomics on $\mathrm{HH}$ design in terms of heel height, contact insole, and HBS have not yet been summarized. It is essentially needed to reach a consensus for shoe manufacturers and users on what kind of high-heeled shoes or insole is most optimal for women. Therefore, this systematic review is aimed at concluding studies that have provided a specific way to effectively offset the negative effects of wearing $\mathrm{HH}$ in the case of women. Our investigations included heel height, insole, and HBS as parameters.

\section{Materials and Methods}

2.1. Design Data Sources, Search Strategy, and Study Selection. This systemic review was carried out in accordance with the PRISMA statement [23]. To identify relevant papers, a bibliographical search was conducted in four databases: Web of Science, PubMed, Scopus, and Embase. A manual search was performed in OpenGrey literature in April 2020. In some cases, YDG was responsible for contacting author by e-mail to obtain supplement information. The detailed electronic search was as follows: "high heels", "high-heeled shoes", "women's footwear", "heel height", "biomechanics", "comfort height", "heel base size", "kinematic parameters", "kinetic parameters", "insole measurements", and "insert". These keywords are combined and searched on each database. The first and second author (MWZ and CJ) independently performed relevance article screening, which involved the title, abstract, full-text, and data extraction examination.

2.2. Eligibility Criteria. The eligibility of selecting papers was estimated according to the following inclusion criteria: (1) the articles had to focus primarily on healthy women wearing HH shoes, (2) the articles were published in English, (3) fulltext, peer-reviewed, original scientific articles published in journals, (4) the presented data is associated with $\mathrm{HH}$ gait (including spatiotemporal, kinematic, kinetic parameters, and EMG), (5) the articles focused on how to alleviate harmful influences on female health with $\mathrm{HH}$, and (6) the articles had to be retrievable. If the abstract did not present sufficient details for any of the eligibility criteria, the reviewers would browse the full text. Then, if the full text failed to comply with any of the eligibility criteria, it would be deleted.

2.3. Data Extraction and Quality Assessment. The important details of the selected articles were extracted by two independent reviewers (ECT and GF). The following data were retrieved from the selected articles: author, year of publication, participant characteristics, shoe condition, measured variables, purpose, and main result. In case of disagreement in data extraction, another reviewer (CJ) was included into the discussion to reach a consensus.

The principles of McMaster Critical Review Form were conducted to thoroughly estimate methodological quality of all selected studies [24-26]. This review form provided 15 separate elements to assess the various types of experimental studies. A 2-point scoring system has been established, where the rating was defined as follows: "yes" (1 point), "no or not measured," or "not applicable" (0 point). This system can be utilized to appraise whether a study meets the standards for good methodological quality [26].

\section{Results}

3.1. Search Results and Validity. The bibliographical database search identified 906 citations: 276 in PubMed, 243 in Scopus, 187 in Web of Science, and 200 in Embase. Duplicates were deleted leaving a total of 362 articles for evaluation. 276 studies were eliminated since after scanning the titles and abstracts of the retrieved papers, it turned out that the content was inconsistent with the standards. 86 full-text studies were extracted for detailed review, and 78 studies were removed as these failed to meet inclusion criteria. A total of 8 studies were eventually eligible for all inclusion criteria. The detailed search strategy is shown in Figure 1, while the basic information of the selected articles is listed in Table 1. Quality evaluation of each article by the McMaster score form is presented in Table 2. All of the extracted papers were graded from moderate to high rating based on the McMaster critical appraisal tool.

3.2. Overview of the Included Studies. An accurate recommendation for offsetting negative impact on $\mathrm{HH}$ for women is to alter three important parameters, namely, heel height, HBS, and sole insert. The biomechanical investigation of these parameters commonly involve kinematic, kinetic, and perceived stability changes of the lower extremity, such as plantar pressure in a different region of the foot, COP deviation in a gait cycle, spatiotemporal variation, and comfort rating. One included article contained EMG testing to detect muscle activity in the tibialis anterior (TA), medial gastrocnemius (MG), quadriceps (QUA), hamstrings (HAM), and erector spinae (ES) during walking, and one study recorded heart rate as a physiological variable.

3.2.1. Heel Height. Two studies conducted several experiments to determine an appropriate height heel of highheeled shoes in order to reduce disturbance of the locomotor pattern. Based on three different walking speeds, Nadège et al. assessed the effect of nine pairs of heel height $(0 \mathrm{~cm}$, $2 \mathrm{~cm}, 3 \mathrm{~cm}, 4 \mathrm{~cm}, 5 \mathrm{~cm}, 6 \mathrm{~cm}, 7 \mathrm{~cm}, 8 \mathrm{~cm}, 9 \mathrm{~cm}$ ) on kinematic 


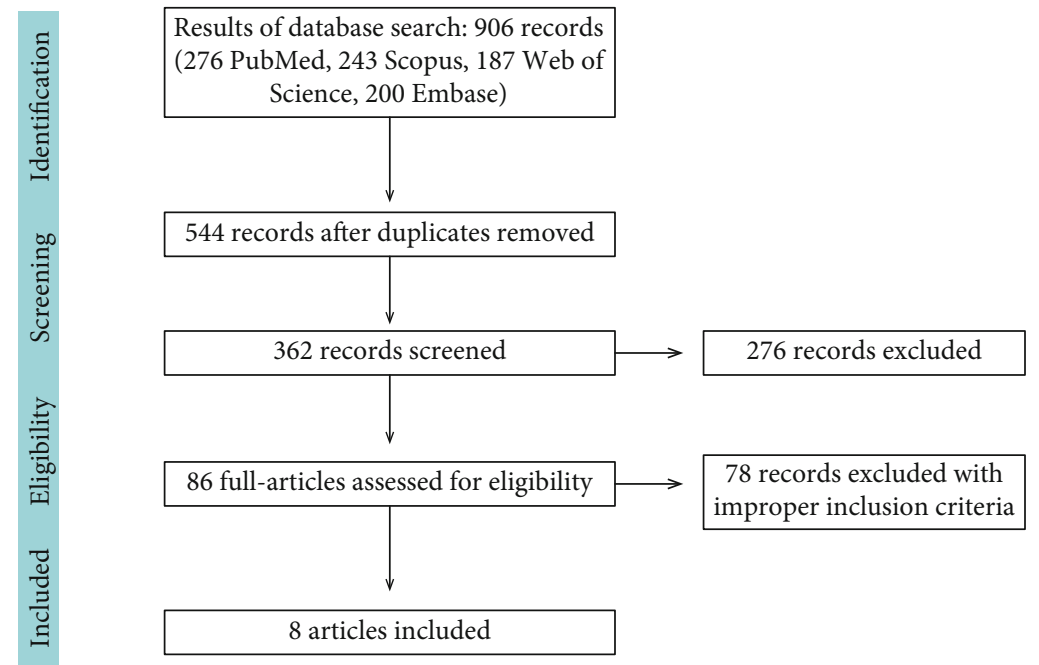

FIgURE 1: Flowchart of the search strategy.

TABLE 1: Basic information on selected articles.

\begin{tabular}{|c|c|c|c|c|}
\hline Number [ref.] & Author/date & Title & Journal & Concentration \\
\hline $1[27]$ & Nadège et al. 2015 & $\begin{array}{l}\text { Wearing high-heeled shoes during gait: } \\
\text { kinematics impact and determination } \\
\text { of comfort height }\end{array}$ & American Journal of Life Sciences & Heel height \\
\hline $2[28]$ & Ko and Lee 2013 & $\begin{array}{c}\text { The changes of COP and foot pressure } \\
\text { after one-hour walking wearing high-heeled } \\
\text { and flat shoes }\end{array}$ & Journal of Physical Therapy Science & Heel height \\
\hline $3[30]$ & Luximon et al. 2015 & $\begin{array}{l}\text { Effects of heel base size, walking speed, } \\
\text { and slope angle on center of pressure } \\
\text { trajectory and plantar pressure when } \\
\text { wearing high-heeled shoes }\end{array}$ & Human Movement Science & HBS \\
\hline 4 [29] & Guo et al. 2012 & $\begin{array}{l}\text { Effect on plantar pressure distribution with } \\
\text { wearing different base size of high-heel } \\
\text { shoes during walking and slow running }\end{array}$ & $\begin{array}{c}\text { Journal of Mechanics in Medicine } \\
\text { and Biology }\end{array}$ & NBS \\
\hline $5[31]$ & Hong et al. 2013 & $\begin{array}{l}\text { Effect of shoe heel height and total-contact } \\
\text { insert on muscle loading and foot stability } \\
\text { while walking }\end{array}$ & Foot and Ankle Society & Insert insole \\
\hline $6[7]$ & Li et al. 2010 & $\begin{array}{l}\text { Biomechanical effects of foam inserts on } \\
\text { forefoot load during the high-heeled gait: } \\
\text { a pilot study }\end{array}$ & $\begin{array}{c}\text { Journal of Mechanics in Medicine } \\
\text { and Biology }\end{array}$ & Insert insole \\
\hline $7[8]$ & Hong et al. 2005 & $\begin{array}{c}\text { Influence of heel height and shoe insert } \\
\text { on comfort perception and biomechanical } \\
\text { performance of young female adults } \\
\text { during walking }\end{array}$ & Foot and Ankle International & Insert insole \\
\hline $8[22]$ & Yung and Wei 2005 & $\begin{array}{l}\text { Effects of shoe inserts and heel height on } \\
\text { foot pressure, impact force, and perceived } \\
\text { comfort during walking }\end{array}$ & Applied Ergonomics & Insert insole \\
\hline
\end{tabular}

parameters, in which the stride length (SL), swing phase (DSwp), duration of the stance phase (DStp), swing phase (DSwP), and gait ratio were included, as well as heart rate [27]. The results indicated that the most comfortable heel height is $4.13 \pm 0.34 \mathrm{~cm}$, which is accompanied with less disruptive locomotor pattern and optimal heart rate, compared to other heights. Differently, Ko and Lee determined the most comfortable heel height for $\mathrm{HH}$ shoes by detecting the displacement of the COP and plantar pressure change after walking for 1 hour in $0.5 \mathrm{~cm}, 4 \mathrm{~cm}$, and $9 \mathrm{~cm}$ shoes, respectively [28]. Results presented that $4 \mathrm{~cm}$ heel height is the most suitable, since this height is accompanied with stable COP tendency and less plantar pressure than walking in $0.5 \mathrm{~cm}$ or $9 \mathrm{~cm}$ shoes. Details are presented in Table 3.

3.2.2. HBS. Two studies were associated with the effect of HBS on distribution of plantar pressure patterns, COP trajectory, and perceived comfort. A large HBS demonstrated 
TABle 2: Methodological quality of included studies by using the McMaster critical appraisal form.

\begin{tabular}{|c|c|c|c|c|c|c|c|c|c|c|c|c|c|c|c|c|c|c|}
\hline \multirow{2}{*}{ Number } & \multirow[t]{2}{*}{ Study design } & \multirow[t]{2}{*}{ Level } & \multicolumn{15}{|c|}{ Items } & \multirow[t]{2}{*}{ Score } \\
\hline & & & 1 & 2 & 3 & 4 & 5 & 6 & 7 & 8 & 9 & 10 & 11 & 12 & 13 & 14 & 15 & \\
\hline 1 & CCT & III-2 & $\sqrt{ }$ & $\sqrt{ }$ & $\sqrt{ }$ & $\sqrt{ }$ & $\sqrt{ }$ & $\sqrt{ }$ & $\mathrm{x}$ & $\vec{V}$ & $\mathrm{n} / \mathrm{a}$ & $\sqrt{ }$ & $\sqrt{ }$ & $\sqrt{ }$ & $\sqrt{ }$ & $\mathrm{x}$ & $\sqrt{ }$ & $12 / 14$ \\
\hline 2 & CCT & III-2 & $\sqrt{ }$ & $\sqrt{ }$ & $\sqrt{ }$ & $\sqrt{ }$ & $\sqrt{ }$ & $\mathrm{x}$ & $\sqrt{ }$ & $\sqrt{ }$ & $\mathrm{n} / \mathrm{a}$ & $\sqrt{ }$ & $\sqrt{ }$ & $\sqrt{ }$ & $\sqrt{ }$ & $\mathrm{x}$ & $\sqrt{ }$ & $12 / 14$ \\
\hline 3 & CCT & III-2 & $\sqrt{ }$ & $\sqrt{ }$ & $\sqrt{ }$ & $\sqrt{ }$ & $\sqrt{ }$ & $\mathrm{x}$ & $\sqrt{ }$ & $\sqrt{ }$ & $\mathrm{n} / \mathrm{a}$ & $\sqrt{ }$ & $\sqrt{ }$ & $\sqrt{ }$ & $\sqrt{ }$ & $\sqrt{ }$ & $\sqrt{ }$ & $13 / 14$ \\
\hline 4 & СCT & III-2 & $\sqrt{ }$ & $\sqrt{ }$ & $\sqrt{ }$ & $\sqrt{ }$ & $\sqrt{ }$ & $\mathrm{x}$ & $\sqrt{ }$ & $\sqrt{ }$ & $\mathrm{n} / \mathrm{a}$ & $\sqrt{ }$ & $\sqrt{ }$ & $\sqrt{ }$ & $\sqrt{ }$ & $\mathrm{x}$ & $\sqrt{ }$ & $12 / 14$ \\
\hline 5 & CCT & III-2 & $\sqrt{ }$ & $\sqrt{ }$ & $\sqrt{ }$ & $\sqrt{ }$ & $\sqrt{ }$ & $\mathrm{x}$ & $\sqrt{ }$ & $\sqrt{ }$ & $\mathrm{n} / \mathrm{a}$ & $\sqrt{ }$ & $\sqrt{ }$ & $\sqrt{ }$ & $\sqrt{ }$ & $\mathrm{x}$ & $\sqrt{ }$ & $12 / 14$ \\
\hline 6 & СCT & III-2 & $\sqrt{ }$ & $\sqrt{ }$ & $\sqrt{ }$ & $\sqrt{ }$ & $\mathrm{x}$ & $\mathrm{x}$ & $\sqrt{ }$ & $\sqrt{ }$ & $\mathrm{n} / \mathrm{a}$ & $\sqrt{ }$ & $\sqrt{ }$ & $\sqrt{ }$ & $\sqrt{ }$ & $\sqrt{ }$ & $\sqrt{ }$ & $12 / 14$ \\
\hline 7 & CCT & III-2 & $\sqrt{ }$ & $\sqrt{ }$ & $\sqrt{ }$ & $\sqrt{ }$ & $\sqrt{ }$ & $\mathrm{x}$ & $\sqrt{ }$ & $\sqrt{ }$ & $\mathrm{n} / \mathrm{a}$ & $\sqrt{ }$ & $\sqrt{ }$ & $\sqrt{ }$ & $\sqrt{ }$ & $\mathrm{x}$ & $\sqrt{ }$ & $12 / 14$ \\
\hline 8 & $\mathrm{CCT}$ & III-2 & $\sqrt{ }$ & $\sqrt{ }$ & $\sqrt{ }$ & $\sqrt{ }$ & $\sqrt{ }$ & $\mathrm{x}$ & $\sqrt{ }$ & $\sqrt{ }$ & $\mathrm{n} / \mathrm{a}$ & $\sqrt{ }$ & $\sqrt{ }$ & $\sqrt{ }$ & $\sqrt{ }$ & $\mathrm{x}$ & $\sqrt{ }$ & $12 / 14$ \\
\hline
\end{tabular}

Level of evidence (based on NHMRC hierarchy); CCT: control clinical trial; FU/RCT: follow-up study from randomized control trial. $\sqrt{ }$ : yes; $\mathrm{x}$ : no/not reported; n/a: not applicable. McMaster Items: (1) study purpose clearly stated; (2) background literature reviewed; (3) appropriate research design; (4) sample described in detail; (5) sample size justified; (6) outcome measure reliability reported; (7) outcome measure validity reported; (8) intervention described; (9) contamination avoided; (10) cointervention avoided; (11) results reported in terms of statistical significance; (12) appropriate analysis method; (13) clinical significance reported; (14) dropouts reported; (15) appropriate conclusion.

smaller maximal peak pear pressure in the rearfoot, midfoot, and forefoot compared to small HBS $[29,30]$. It must be noted that the scale of HBS affects the COP location in the anterior-posterior direction at the end of the stance phase. The COP deviations are increased with a small HBS when compared to a large HBS [30]. Only one study reported information about the stability as a function of HBS. It can be concluded that a large HBS can lead to a more stable gait during walking with $\mathrm{HH}$ [30]. Details are presented in Table 4, and different sizes of HBS are shown in Figure 2(b).

3.2.3. Insert Insole. Four included studies evaluated the effect of insert insole on kinematic, kinetic, EMG, and comfort rating of the lower extremity, but different types of insole were used for each study. One study investigated how subject's rearfoot kinematic, muscle activity, and subjective comfort were affected by TCI which were designed from rearfoot to metatarsal head during walking with $\mathrm{HH}$ (Figure 2(b) [31]. When compared with a noninsert condition, results showed that the use of a TCI could reduce peak MG by $19.0 \%$ and peak ES by $21.5 \%$ in $\mathrm{HH}$ with $7.6 \mathrm{~cm}$, and rearfoot inversion angle was significantly decreased. But this study did not present kinetic variation of the foot. Another included article used an insole from the rearfoot to metatarsal head (TCI II) that was designed by the orthotist to fit each participants' foot to determine the effect of shoe inserts on plantar pressure, GRF, and perceived comfort during walking in different heel height shoes $(1.0 \mathrm{~cm}, 5.1 \mathrm{~cm}, 7.6 \mathrm{~cm}$ ) (Figure 2(b)) [8]. Results showed that the peak pressure of the medial forefoot reduced by using TCL compared with noninsert shoes, and it was more effective to use TCI in the higher heels than lower and flat heels. Furthermore, Yung and Wei also found that a TCI decreased heel pressure by $25 \%$, medial forefoot pressure by $24 \%$, and impact force by $33 \%$ [22].

While the heel cup pad could decrease the heel pressure and impact force and the use of single arch support inserts can attenuate the medial forefoot pressure, no special changes to the metatarsal pad using measured parameters were found [22]. The medial forefoot (MF) has been considered the most sensitive area in response to heel height varia- tion $[7,22,32,33]$. The effect of four different types of foam insoles (soft $5 \mathrm{~mm}$, soft $10 \mathrm{~mm}$, hard $5 \mathrm{~mm}$, hard $100 \mathrm{~mm}$ ) in the targeted MF region on plantar pressure was tested. There was a great advantage in soft $5 \mathrm{~mm}$ to reduce peak pressure by $26 \%$, impact force by $27 \%$ in MF region compared to the noninsert condition [7]. All the above insole types are presented in Figure 2(a). More details on female insert insoles are presents in Table 5.

\section{Discussion}

To reach a full understanding of how the design factors of high-heeled shoes affect locomotor pattern, disturbance of plantar pressure, and perceived comfort is crucial. This review identified 8 articles, which appraised either the effect of heel height, HBS, or insert insole on lower limb kinematic, kinetic, or EMG during waking with $\mathrm{HH}$, as well as perceived comfort.

4.1. Heel Height Studies. There are only two studies that evaluated the comfort heel height of $\mathrm{HH}$ by using different methods, and a consensus has been formed that shows that the appropriate heel height in high-heeled shoes is $4.13 \pm$ $0.34 \mathrm{~cm}[27,28]$. In addition, this result is also consistent with Ko who reported that the preferable heel height was between $3 \mathrm{~cm}$ and $5 \mathrm{~cm}$, but this article as a conference paper failed to be selected in this review [34]. A growing number of researches indicate that musculoskeletal systems are directly modified from wearing $\mathrm{HH}$. On the other hand, the human foot naturally presents a moderate imbalance in body weight (BW) distribution; i.e., $43 \%$ of $\mathrm{BW}$ is loaded to the foot front, with the remaining $57 \%$ at the heel portion when walking barefoot. For that reason, a slight heel height shoe $(2 \mathrm{~cm})$ is recommended to be used by orthopedic specialists, since it can balance the distribution of plantar pressure to relieve rearfoot load [21]. But these outcomes depend on short-term testing rather than for a long period. Therefore, the results of a suitable heel height in included articles may not predict the impact of wearing high-heeled shoes in the long term. 


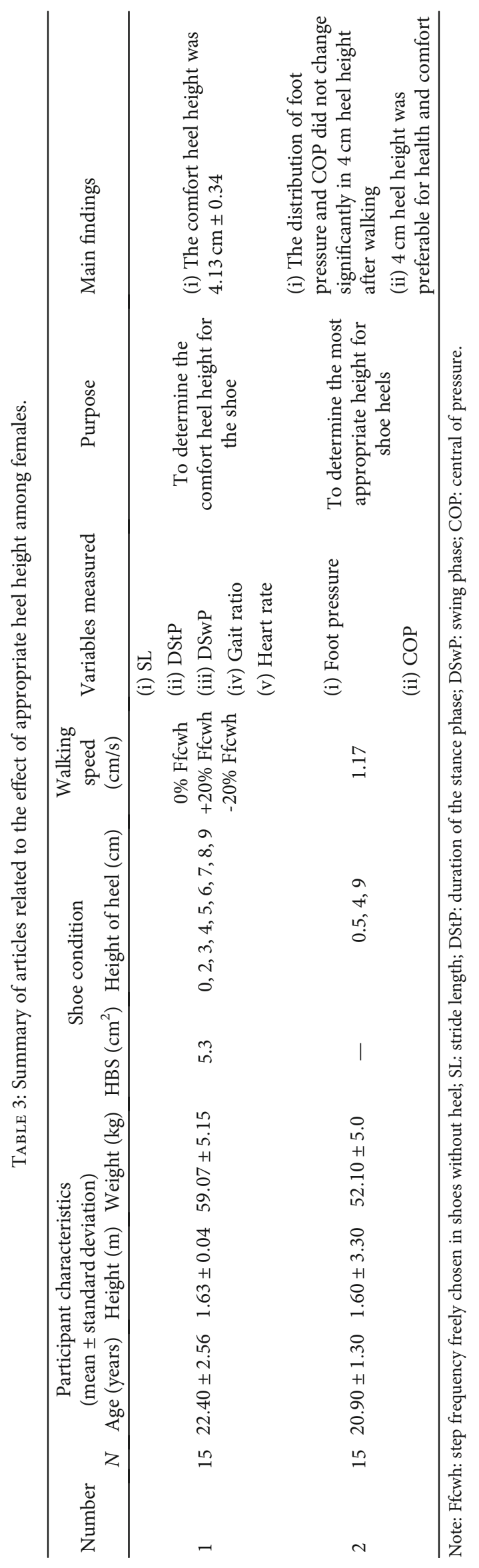




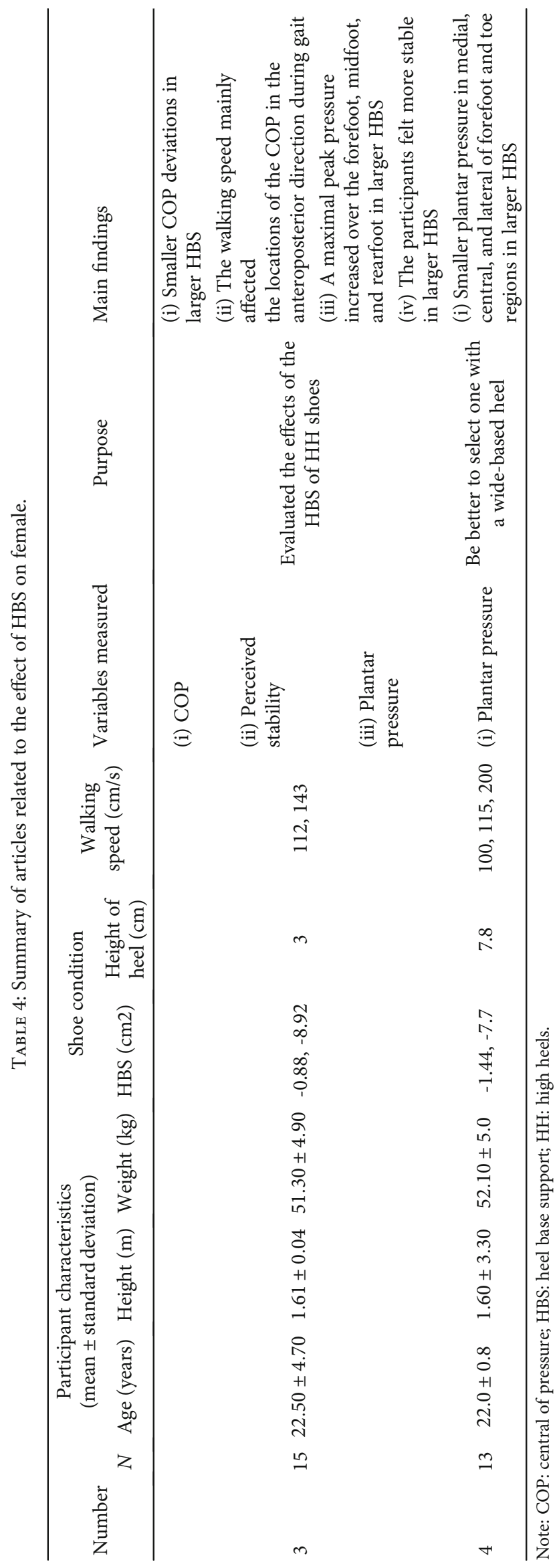




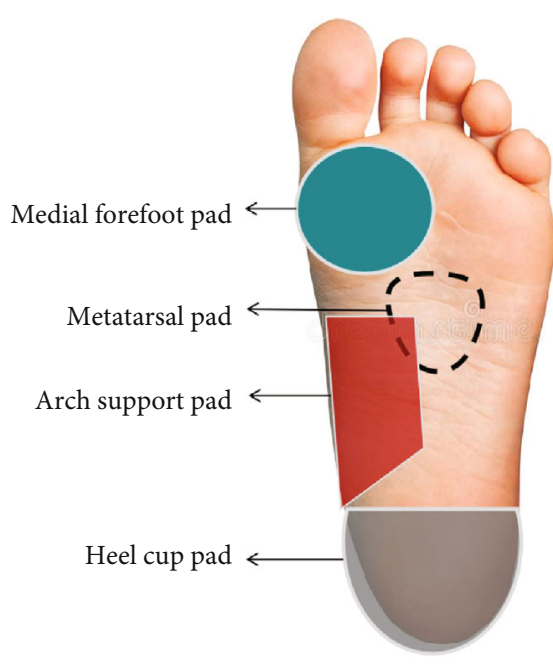

(a)

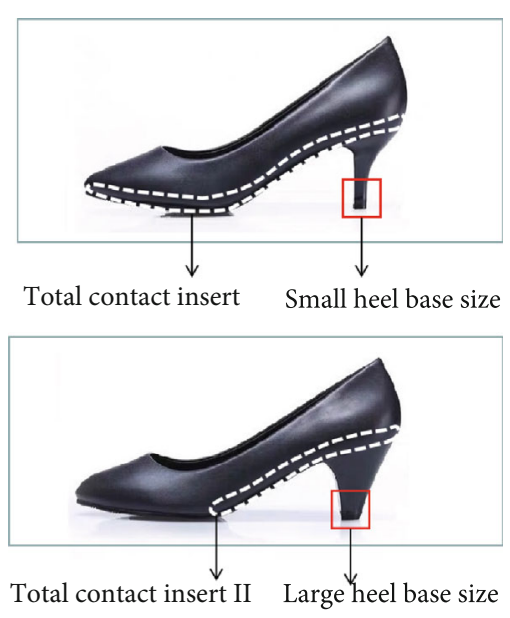

(b)

Figure 2: (a) The different insert pads mentioned in included studies. (b) The total contact insert, total contact insert II (from rearfoot to metatarsal head), and small and large heel base size mentioned in included studies. Note: (a) and (b) do not represent the actual ones used in the included study.

4.2. HBS Studies. The scale of HBS is another important factor influencing locomotor pattern during gait with $\mathrm{HH}$. The narrow heels are the most commonly used design in $\mathrm{HH}$ which increase plantar pressure, especially in the heel region and lead to instability $[22,35,36]$. Luximon et al. noted that the maximal peak pressure uniformly increased over the whole plantar in large HBS, whereas a narrowed HBS presented higher maximal peak pressure in the toe region [30]. This result is partially similar to Guo et al. whose research showed that the plantar pressure of hallux was significantly increased in small HBS compared to large HBS [29]. Except for the impact of heel height, the narrow HBS may be a direct reason contributing to hammer toe which is caused by excessive pressure on the metatarsal-phalangeal region during walking with $\mathrm{HH}$. Additionally, a smaller HBS presented a larger COP deviation which triggered gait instability, where the toes had to grip the sole of shoes to keep stable. This scenario may be another reason that could lead to the development of a hammer toe when wearing $\mathrm{HH}$ [30].

It must be noted that only one heel height was used to measure the function of using different HBS in two selected studies. Although previous researchers suggested that a decreased HBS rather than an increased heel height was the main element for reducing stability during walking with $\mathrm{HH}$ [37], the different sizes of HBS combined with diverse heel height should be assessed in the future to further confirm the effectiveness of HBS on gait stabilization.

4.3. Insert Insole Studies. Insert insole has been widely used in footwear to improve perceived comfort, absorbing energy attenuating impact forces, redistribute the plantar pressure, and reduce the risk of movement-related injury [38-40]. The various insert designs presented different kinetic modifications during walking with $\mathrm{HH}$. For instance, Yung and Wei indicated that a heel cup pad reduced pressure by $24.3 \%$ and impact force by $18.6 \%$ in the heel region when wearing $\mathrm{HH}$
[22]. An arch support insole decreased peak pressure by $15 \%$ in the medial forefoot region and raised the pressure by $125.6 \%$ in the midfoot region, since it was used to prevent depression of the longitudinal arch during weight bearing, thereby alleviating the tension of the plantar aponeurosis $[22,41,42]$. Weight bearing can be transferred from the forefoot to the longitudinal and metatarsal arches by the metatarsal pad; however, no changes in pressure and impact forces were found in the medial forefoot region reported by Yung and Wei [22]. Furthermore, medial forefoot pads with different foam hardness and thickness were utilized; and the results showed that the thick soft pad can effectively reduce larger pressure and impact force caused by $\mathrm{HH}$ in the medial forefoot when compared to other types [7, 43].

In terms of using TCI, three included studies indicated that TCI relieved pressure and impact force on multiple areas of the foot simultaneously and significantly improved perceived comfort during walking with $\mathrm{HH}[8,22,31]$. The TCI provides a highly conforming fit between the foot and the contact surface of the insole, as well as spreading and redistributing pressure over the rearfoot, midfoot, and forefoot. Notably, the current research notes that the use of TCI is the most effective way to attenuate pressure in comparison to other single pads during walking with $\mathrm{HH}$. Further studies are needed to evaluate the effect of different thicknesses and material properties of TCI on load and pressure redistribution during walking with $\mathrm{HH}$ shoes. What is more, the effectiveness of insoles also needs to be estimated in the long term to determine whether this type of intervention should be recommended for women with high heels-related foot problems.

4.4. Limitations and Future Direction. The most obvious limitation in this review is the small sample size. Only 8 studies met our inclusion criteria hence the reason why a metaanalysis was not conducted. In addition, the effects of 


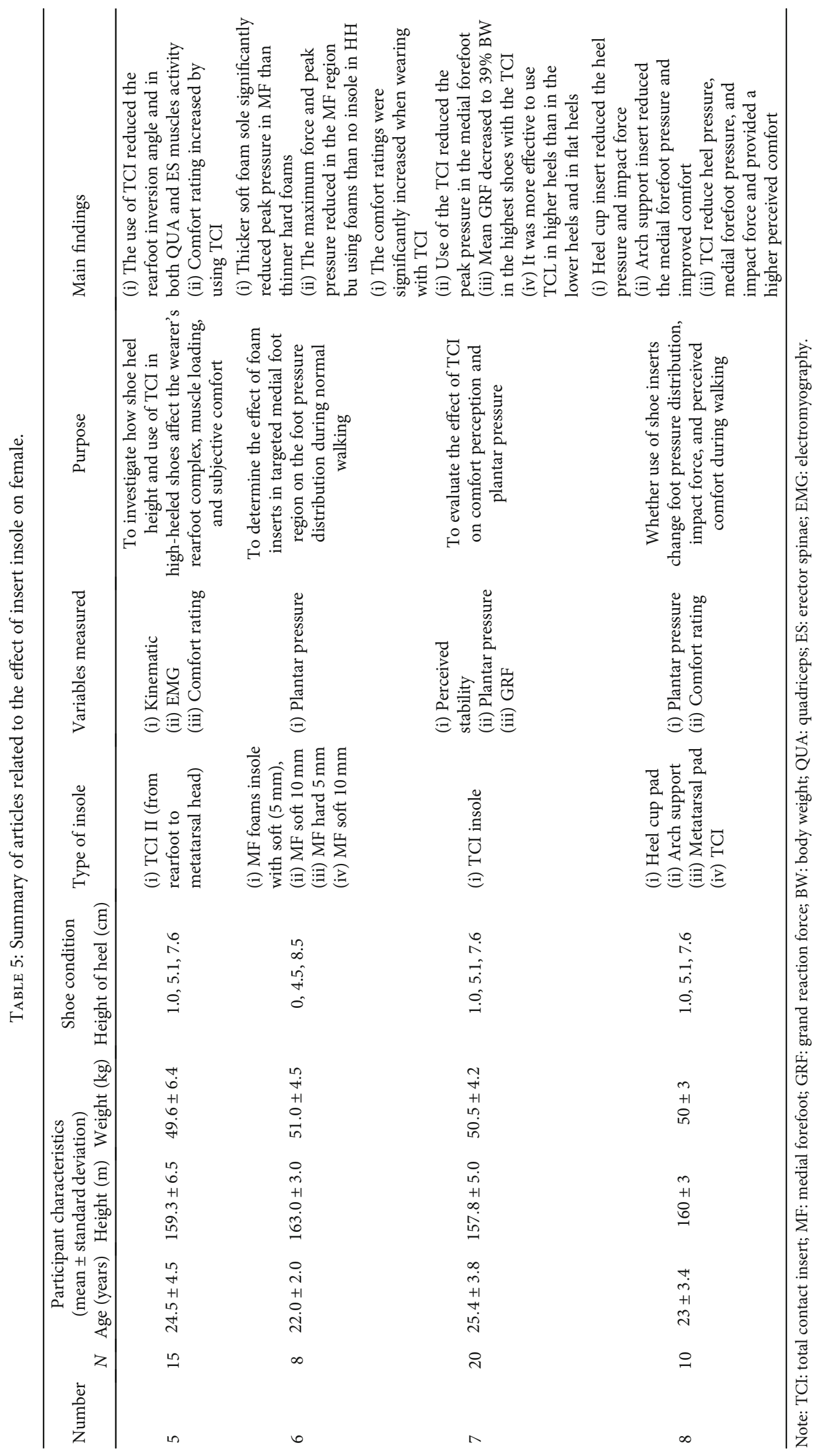


walking/running speed on locomotor pattern during highheeled gait were not studied because there are a wide range of variables and different experimental conditions that would need to be taken into consideration.

It is worth thinking about $\mathrm{HH}$ in relation to finite element model analysis and laboratory tests to determine what kind of material properties, hardness, and thickness of insert insole are optimal to minimize the negative impacts of wearing $\mathrm{HH}$. On the other hand, the age, height, and body mass are important parameters in wearing $\mathrm{HH}$; the age affects muscle strength, the height may affect joint moment, and bodyweight directly related to load increase. Future studies should be aimed at providing personal recommendations for $\mathrm{HH}$ in terms of choosing the heel height and HBS size based on the individual characteristics that involve weight, height, and age. It seems likely achieved by conducting a comprehensive study that combines the numerical simulation, finite element model analysis, and a large number of sample experiments in the long term.

\section{Conclusions}

We have systematically reviewed studies focused on factors that aim to counter the adverse impacts on high-heeled shoes. The effects of heel height, heel base size, and insert insole on the biomechanical of lower extremity and perceived comfort are concluded. Some evidence demonstrates that (i) the range of appropriate heel height for wearing $\mathrm{HH}$ is $3.76 \mathrm{~cm}$ to $4.47 \mathrm{~cm}$; (ii) compared to small heel base size, the larger ones effectively increase gait stability, reduce risk of ankle injury, and improve comfort rating during walking with $\mathrm{HH}$; and (iii) the use of a total contact insert significantly decreases plantar pressure and impact forces on the foot so that a higher perceived comfort is achieved. However, there were some limitations in the data presented in the included articles due to the different methodologies used and a limited number of studies. All the above conclusions need to be further tested in a longer duration experiment. In the future, numerical simulation, finite element model analysis, and a large number of sample experiments should be combined to offer personal recommendations for wearing $\mathrm{HH}$ based on the individuals' characteristics.

\section{Conflicts of Interest}

The authors declare that they have no conflicts of interest.

\section{Acknowledgments}

This study was sponsored by the by National Natural Science Foundation of China (No. 81772423) and K. C. Wong Magna Fund in Ningbo University.

\section{References}

[1] C. J. Ebbeling, J. Hamill, and J. A. Crussemeyer, "Lower extremity mechanics and energy cost of walking in highheeled shoes," Journal of Orthopaedic \& Sports Physical Therapy, vol. 19, no. 4, pp. 190-196, 1994.
[2] M. Esenyel, K. Walsh, J. G. Walden, and A. Gitter, "Kinetics of high-heeled gait," Journal of the American Podiatric Medical Association, vol. 93, no. 1, pp. 27-32, 2003.

[3] D. D. Barkema, T. R. Derrick, and P. E. Martin, "Heel height affects lower extremity frontal plane joint moments during walking," Gait \& Posture, vol. 35, no. 3, pp. 483-488, 2012.

[4] N. J. Cronin, R. S. Barrett, and C. P. Carty, "Long-term use of high-heeled shoes alters the neuromechanics of human walking," Journal of Applied Physiology, vol. 112, no. 6, pp. 10541058, 2012.

[5] C. M. Lee, E. H. Jeong, and A. Freivalds, "Biomechanical effects of wearing high-heeled shoes," International Journal of Industrial Ergonomics, vol. 28, no. 6, pp. 321-326, 2001.

[6] M. G. Blanchette, J. R. Brault, and C. M. Powers, "The influence of heel height on utilized coefficient of friction during walking," Gait \& Posture, vol. 34, no. 1, pp. 107-110, 2011.

[7] J. S. Li, Y. D. Gu, X. J. Ren, M. J. Lake, and Y. J. Zeng, "Biomechanical effects of foam inserts on forefoot load during the high-heeled gait: a pilot study," Journal of Mechanics in Medicine and Biology, vol. 10, no. 4, pp. 667-674, 2012.

[8] W. H. Hong, Y. H. Lee, H. C. Chen, Y. C. Pei, and C. Y. Wu, "Influence of heel height and shoe insert on comfort perception and biomechanical performance of young female adults during walking," Foot \& Ankle International, vol. 26, no. 12, pp. 1042-1048, 2005.

[9] D. C. Kerrigan, J. L. Lelas, and M. E. Karvosky, "Women's shoes and knee osteoarthritis," The Lancet, vol. 357, no. 9262, pp. 1097-1098, 2001.

[10] J. C. Menant, S. D. Perry, J. R. Steele, H. B. Menz, B. J. Munro, and S. R. Lord, "Effects of shoe characteristics on dynamic stability when walking on even and uneven surfaces in young and older people," Archives of Physical Medicine and Rehabilitation, vol. 89, no. 10, pp. 1970-1976, 2008.

[11] E. B. Simonsen, M. B. Svendsen, A. Nørreslet et al., "Walking on high heels changes muscle activity and the dynamics of human walking significantly," Journal of Applied Biomechanics, vol. 28, no. 1, pp. 20-28, 2012.

[12] R. Csapo, C. N. Maganaris, O. R. Seynnes, and M. V. Narici, "On muscle, tendon and high heels," Journal of Experimental Biology, vol. 213, no. 15, pp. 2582-2588, 2010.

[13] A. Mika, Ł. Oleksy, P. Mika, A. Marchewka, and B. C. Clark, "The influence of heel height on lower extremity kinematics and leg muscle activity during gait in young and middleaged women," Gait \& Posture, vol. 35, no. 4, pp. 677-680, 2012.

[14] D. J. Stefanyshyn, B. M. Nigg, V. Fisher, B. O'Flynn, and W. Liu, "The influence of high heeled shoes on kinematics, kinetics, and muscle EMG of normal female gait," Journal of Applied Biomechanics, vol. 16, no. 3, pp. 309-319, 2000.

[15] M. R. Titchenal, J. L. Asay, J. Favre, T. P. Andriacchi, and C. R. $\mathrm{Chu}$, "Effects of high heel wear and increased weight on the knee during walking," Journal of Orthopaedic Research, vol. 33, no. 3, pp. 405-411, 2015.

[16] J. Yu, D. W.-C. Wong, H. Zhang, Z.-P. Luo, and M. Zhang, "The influence of high-heeled shoes on strain and tension force of the anterior talofibular ligament and plantar fascia during balanced standing and walking," Medical Engineering \& Physics, vol. 38, no. 10, pp. 1152-1156, 2016.

[17] M. Wang, Y. Gu, and J. S. Baker, "Analysis of foot kinematics wearing high heels using the Oxford foot model," Technology and Health Care, vol. 26, no. 5, pp. 815-823, 2018. 
[18] M. Wang, Z. Yan, G. Fekete, J. S. Baker, and Y. Gu, "The kinematics of the spine and lower limbs on sagittal plane in highheeled gait," Journal of Medical Imaging and Health Informatics., vol. 8, no. 5, pp. 973-978, 2018.

[19] Y. Zhang, M. Wang, J. Awrejcewicz, G. Fekete, F. Ren, and Y. Gu, "Using gold-standard gait analysis methods to assess experience effects on lower-limb mechanics during moderate high-heeled jogging and running," Journal of Visualized Experiments, vol. 127, pp. 1-7, 2017.

[20] American Podiatric Medical Association, Public opinion research on foot health and care, APMA, USA, 2014.

[21] A. C. Broega, M. Righetto, and R. Ribeiro, "Female high heel shoes: a study of comfort," IOP Conference Series: Materials Science and Engineering, vol. 254, no. 23, pp. 23-27, 2017.

[22] H. L. Yung and H. H. Wei, "Effects of shoe inserts and heel height on foot pressure, impact force, and perceived comfort during walking," Applied Ergonomics, vol. 36, no. 3, pp. 355362, 2005.

[23] D. Moher, A. Liberati, J. Tetzlaff, and D. G. Altman, "Preferred reporting items for systematic reviews and meta-analyses: the PRISMA statement," Annals of Internal Medicine, vol. 151, no. 4, pp. 264-9, W64, 2009.

[24] M. Law, D. Steward, N. Pollock, L. Letts, J. Bosch, and M. Westmorland, Critical Review Form Quantitative Studies, McMaster University, Hamilton, 2019.

[25] L. Letts, S. Wilkins, M. Law, D. Stewart, J. Bosch, and M. Westmorland, Critical review form-qualitative studies (version 2.0), vol. 51, no. 2, 2007McMaster University, 2007.

[26] T. Merlin, A. Weston, and R. Tooher, "Extending an evidence hierarchy to include topics other than treatment: revising the Australian 'levels of evidence'," BMC Medical Research Methodology, vol. 9, no. 1, pp. 34-40, 2009.

[27] K. F. E. Nadège, F. Jean-Marie, L. M. Mansourou, G. Polycarpe, A. Y. Gabriel, and L. Sophia, "Wearing high heel shoes during gait: kinematics impact and determination of comfort height," American Journal of Life Sciences, vol. 3, no. 2, pp. 56-61, 2015.

[28] D. Y. Ko and H. S. Lee, "The changes of COP and foot pressure after one hour's walking wearing high-heeled and flat shoes," Journal of Physical Therapy Science, vol. 25, no. 10, pp. 13091312, 2013.

[29] L. Y. Guo, C. F. Lin, C. H. Yang et al., "Effect on plantar pressure distribution with wearing different base size of high-heel shoes during walking and slow running," Journal of Mechanics in Medicine and Biology, vol. 12, no. 1, pp. 12-18, 2012.

[30] Y. Luximon, Y. Cong, A. Luximon, and M. Zhang, "Effects of heel base size, walking speed, and slope angle on center of pressure trajectory and plantar pressure when wearing high-heeled shoes," Human Movement Science, vol. 41, pp. 307-319, 2015.

[31] W. H. Hong, Y. H. Lee, Y. H. Lin, S. F. Tang, and H. C. Chen, "Effect of shoe heel height and total-contact insert on muscle loading and foot stability while walking," Foot \& Ankle International, vol. 34, no. 2, pp. 273-281, 2013.

[32] E. Morag and P. R. Cavanagh, "Structural and functional predictors of regional peak pressures under the foot during walking," Journal of Biomechanics, vol. 32, no. 4, pp. 359-370, 1999.

[33] C. M. Speksnijder, R. J. Munckhof, S. A. Moonen, and G. H. Walenkamp, "The higher the heel the higher the forefootpressure in ten healthy women," The Foot, vol. 15, no. 1, pp. 17-21, 2005.
[34] P. H. Ko, T. Y. Hsiao, J. H. Kang, T. G. Wang, Y. W. Shau, and C. L. Wang, "Relationship between plantar pressure and soft tissue strain under metatarsal heads with different heel heights," Foot \& Ankle International, vol. 30, no. 11, pp. 1111-1116, 2009.

[35] H. B. Menz and M. E. Morris, "Footwear characteristics and foot problems in older people," Gerontology, vol. 51, no. 5, pp. 346-351, 2005.

[36] W. W. Shen, J. B. Ma, J. S. Li, and Y. D. Gu, "Study on plantar pressure during tilt walking in young group," Journal of Convergence Information Technology, vol. 8, no. 2, pp. 711-717, 2013.

[37] H. L. Chien, T. W. Lu, and M. W. Liu, "Control of the motion of the body's center of mass in relation to the center of pressure during high-heeled gait," Gait \& Posture, vol. 38, no. 3, pp. 391-396, 2013.

[38] R. C. Dinato, A. P. Ribeiro, M. K. Butugan, I. L. R. Pereira, A. N. Onodera, and I. C. N. Sacco, "Biomechanical variables and perception of comfort in running shoes with different cushioning technologies," Journal of Science and Medicine in Sport, vol. 18, no. 1, pp. 93-97, 2015.

[39] Y. Urabe, N. Maeda, S. Kato, H. Shinohara, and J. Sasadai, "Effect of shoe insole for prevention and treatment of lower extremity injuries," The Journal of Physical Fitness and Sports Medicine, vol. 3, no. 4, pp. 385-398, 2014.

[40] A. Herbaut, E. Simoneau-Buessinger, F. Barbier, F. Cannard, and N. Guéguen, "A reliable measure of footwear upper comfort enabled by an innovative sock equipped with textile pressure sensors," Ergonomics, vol. 59, no. 10, pp. 1327-1334, 2016.

[41] G. F. Kogler, S. E. Solomonidis, and J. P. Paul, "Biomechanics of longitudinal arch support mechanisms in foot orthoses and their effect on plantar aponeurosis strain," Clinical biomechanics, vol. 11, no. 5, pp. 243-252, 1996.

[42] D. Sun, Y. Gu, Q. Mei, Y. Shao, J. Sun, and J. Fernandez, "Effect of heel heights on female postural control during standing on a dynamic support surface with sinusoidal oscillations," Journal of Motor Behavior, vol. 49, no. 3, pp. 281-287, 2017.

[43] B. Zhang and Q. Lu, "A current review of foot disorder and plantar pressure alternation in the elderly," Physical Activity and Health, vol. 4, no. 1, pp. 95-106, 2020. 